\title{
Update on the relationship between the North Atlantic Oscillation and Calanus finmarchicus
}

\author{
David G. Kimmel ${ }^{1,3, *}$, Sultan Hameed ${ }^{2}$ \\ ${ }^{1}$ Horn Point Laboratory, University of Maryland Center for Environmental Science, 2020 Horns Point Road, Cambridge, \\ Maryland 21613, USA \\ ${ }^{2}$ Marine Sciences Research Center, The University at Stony Brook, Stony Brook, New York 11794-5000, USA \\ ${ }^{3}$ Present address: Department of Biology/Institute for Coastal Science and Policy, East Carolina University, Greenville, \\ North Carolina 27858, USA
}

\begin{abstract}
The relationship between climate, represented by the North Atlantic Oscillation (NAO), and the calanoid copepod Calanus finmarchicus has been extensively studied. The correlation between NAO and C. finmarchicus has broken down (post-1995). In the present study, we revisit the relationship between $C$. finmarchicus and the NAO. Our reanalysis shows that previous treatment of this data did not take into account 2 aspects of both the $C$. finmarchicus and NAO index time-series: (1) the presence of significant trends and (2) significant autocorrelation. Our analysis suggests that previously reported relationships between NAO and $C$. finmarchicus abundance can be explained largely by the trends in both data series. Removing the trend from both time-series resulted in a decrease in the amount of $C$. finmarchicus abundance variability explained by the NAO. Trend removal eliminated the autocorrelation from the NAO time-series, but not from the C. finmarchicus time-series. Partial autocorrelation analysis showed that the autocorrelation present in the $C$. finmarchicus time-series is only found at a lag of $1 \mathrm{yr}$, suggesting strong, year-to-year connectivity in this population. We included the lagged $C$. finmarchicus abundance into a regression with the NAO and found that $C$. finmarchicus variability is explained by the previous year's abundance and, to a much smaller extent, by NAO variability. Limiting the time-series to the most recent 22 yr period (1981 to 2002) showed that the NAO is no longer correlated to C. finmarchicus abundance, and the autocorrelation in the $C$. finmarchicus abundance series also appears to be weakening.
\end{abstract}

KEY WORDS: North Atlantic Oscillation · Calanus finmarchicus · Trend · Autocorrelation • Time-series Resale or republication not permitted without written consent of the publisher

\section{INTRODUCTION}

The relationship between climate variability and marine organisms has long been recognized (Cushing \& Dickson 1976). Interest in this subject has typically centered on large spatial-scale climate indices, e.g. the North Atlantic Oscillation (NAO), El Niño Southern Oscillation (ENSO) and the Pacific Decadal Oscillation (PDO). Strong relationships have been found among the NAO (Ottersen et al. 2001, Parsons \& Lear 2001), ENSO (Pearcy \& Schoener 1987, Sugimoto et al. 2001), PDO (Hollowed et al. 2001, Royer et al. 2001) and the abundance of various marine organisms. In particular, shifts in plankton abundance in relation to climate indices have been well studied in the northeast Atlantic Ocean (e.g. Taylor 1995, Fromentin \& Planque 1996, Planque \& Reid 1998, Planque \& Taylor 1998).

The dominant mesozooplankton species across much of the northeast Atlantic Ocean is the calanoid copepod Calanus finmarchicus. Using Continuous Plankton Recorder (CPR; see Jossi et al. 2003) data for the period 1962 to 1992, Fromentin \& Planque (1996), suggested that long-term changes in C. finmarchicus abundance in the northeast Atlantic were strongly coupled to the NAO. Planque \& Taylor (1998) further extended these analyses by using the position of the 
Gulf Stream north wall, as well as the NAO, to predict C. finmarchicus abundance. Planque \& Reid (1998) developed a linear regression model between $C$. finmarchicus abundance and the NAO for the years 1958 to 1992. Their goal was to use this model to predict C. finmarchicus abundance for 1993 to 1997. They reported that the predictions for 1993 to 1995 were close to the observed values, but found a sharp discrepancy between observations and predictions for the years 1996 to 1997 (Planque \& Reid 1998). C. finmarchicus abundance and NAO index variability have continued to deviate from each other (Fig. 1).

In the present study, we revisit the relationship between Calanus finmarchicus and the NAO. Our results suggest that the coupling between the NAO and C. finmarchicus is weaker than has been assumed in previous literature. The impact of the prior year's $C$. finmarchicus population is the dominant factor in determining the size of the current year's abundance with a small contribution due to NAO-related environmental variability.

\section{MATERIALS AND METHODS}

Zooplankton data were acquired from the Sir Alister Hardy Foundation for Ocean Science and were collected using the CPR (Jossi et al. 2003, Richardson et al. 2006). The area covered by these data can be seen in Fromentin \& Planque (1996, their Fig. 1). We used the same data as Planque \& Fromentin (1996), which consisted of stage $\mathrm{V}$ copepodites and adult Calanus finmarchicus abundance. The data were log-transformed $(x+1)$ prior to analysis. The annual values used were the mean abundance from January to December (Planque \& Fromentin 1996).

The NAO is defined as the difference in normalized sea level pressure (SLP) between Lisbon, Portugal, or
Ponta Delgada, Azores, and Stykkisholmur/Reykjavik, Iceland (Hurrell 1995). The winter (December through March) index of the NAO based on the difference of normalized SLP between Lisbon and Stykkisholmur/ Reykjavik is available at: www.cgd.ucar.edu/cas/ jhurrell/indices.html and was used in the present study. All statistical analyses were performed using S-PLUS (Insightful, see www.insightful.com/products/splus) software package.

\section{RESULTS}

Correlation between NAO and Calanus finmarchicus abundance for the period 1958-2002 is -0.54, i.e. it explains ca. $25 \%$ of the copepod variance (Table 1). When we limit the copepod data to 1958-1992, the correlation with the NAO index is -0.71 , similar to the value -0.76 reported by Planque \& Reid (1998) for the period 1958-1995. Thus, there is a substantial decrease in correlation when the copepod data are extended from 1995-2002. If the time-series is further separated into 2 equal segments (1958-1980 and 1981-2002), the correlation between C. finmarchicus and NAO is significant for the first time period, but not the latter (Table 1).

The Calanus finmarchicus abundance has been in a general downward trend during the period of the present study (Fig. 1). This trend is significant for the time periods 1958 to 2002 and 1958 to 1992 (Table 1). The years 1958 to 1980 also had a negative trend, though it was not significant because of the rise in Calanus during 1976 to 1980 (Table 1, Fig. 1). The NAO also had a significant, positive trend during the 1958 to 2002 and 1958 to 1992 time periods (Table 1). The trend was not present during either of the 2 halves of the data. The NAO has departed from its earlier upward trend (Fig. 1). We removed the trend from the C. finmarchi-

Table 1. Correlation, trend and autocorrelation estimates for Calanus finmarchicus abundance (C. fin) and NAO index and after removal of linear trends using least squares regression. p-values are given in parentheses; values in bold represent significant values with $p<0.05$

\begin{tabular}{|c|c|c|c|c|c|}
\hline \multirow[t]{2}{*}{ Time period } & \multicolumn{2}{|c|}{$\begin{array}{c}\text { Trend } \\
\text { Kendall's } \tau\end{array}$} & \multicolumn{2}{|c|}{$\begin{array}{c}\text { Autocorrelation } \\
\text { Yule-Walker AR(1) } \rho\end{array}$} & \multirow{2}{*}{$\begin{array}{c}\text { Correlation } \\
\text { Pearson's R } \\
\text { C. fin vs. NAO }\end{array}$} \\
\hline & C. fin & $\mathrm{NAO}$ & C. fin & NAO & \\
\hline $1958-2002$ & $-0.67\left(1 \times 10^{-10}\right)$ & $0.31(0.002)$ & $0.85\left(1 \times 10^{-8}\right)$ & $0.40(0.008)$ & $-0.54(0.0001)$ \\
\hline $1958-1992$ & $-0.53\left(7 \times 10^{-6}\right)$ & $0.38(0.001)$ & $0.74(0.00001)$ & $0.47(0.005)$ & $-0.71\left(1 \times 10^{-6}\right)$ \\
\hline $1958-1980$ & $-0.20(0.18)$ & $0.17(0.27)$ & $0.67(0.001)$ & $0.31(0.13)$ & $-0.64(0.001)$ \\
\hline $1981-2002$ & $-0.70\left(5 \times 10^{-6}\right)$ & $-0.08(0.61)$ & $0.74(0.0005)$ & $0.12(0.56)$ & $0.11(0.61)$ \\
\hline \multicolumn{6}{|c|}{ After trend removal } \\
\hline 1958-2002 & $0.03(0.81)$ & $0.03(0.76)$ & $0.60(0.00005)$ & $0.24(0.10)$ & $-0.34(0.02)$ \\
\hline $1958-1992$ & $0.04(0.71)$ & $0.17(0.15)$ & $0.59(0.0004)$ & $0.29(0.08)$ & $-0.48(0.003)$ \\
\hline $1958-1980$ & $0.07(0.67)$ & $0.0004(1)$ & $0.60(0.004)$ & $0.26(0.21)$ & $-0.58(0.003)$ \\
\hline $1981-2002$ & $-0.22(0.16)$ & $-0.23(0.14)$ & $0.31(0.15)$ & $0.21(0.32)$ & $0.05(0.25)$ \\
\hline
\end{tabular}




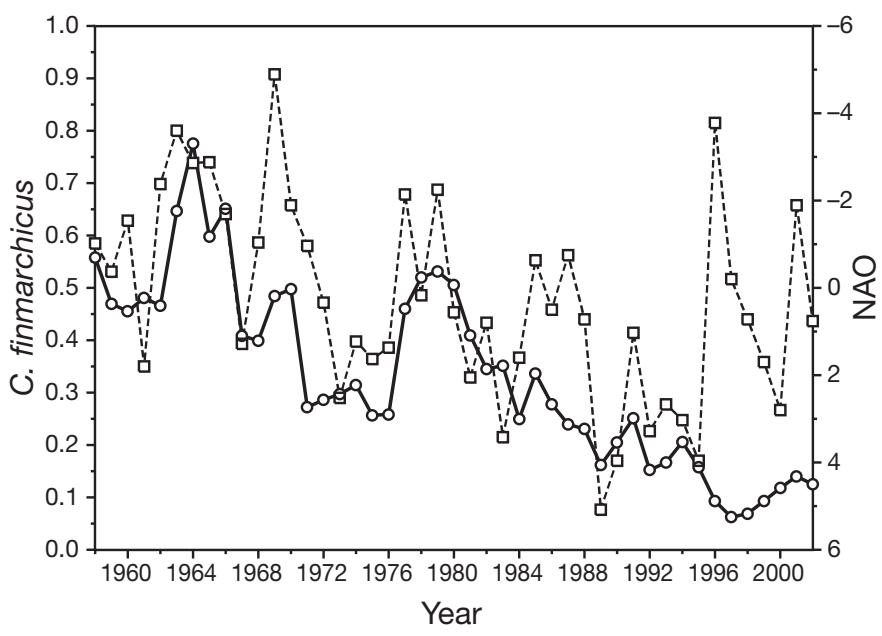

Fig. 1. Calanus finmarchicus. Comparison of copepod abundance from the Continuous Plankton Recorder (CPR) data set used by Fromentin \& Planque (1996) (O) with the winter (December to March) North Atlantic Oscillation (NAO) index (Hurrell 1995) (口). NAO is shown on an inverted scale

cus and NAO time-series using linear regression. The residuals for both time-series did not show a significant trend (Table 1). The trend removal resulted in a decrease in the strength of the correlation between C. finmarchicus and NAO during the time periods 1958 to 2002 and 1958 to 1992 (Table 1). The NAO explained $29 \%$ of the variance in C. finmarchicus abundance with the trends present in both data for the time period 1958 to 2002 (Table 1, Pearson's r =-0.54). After trend removal, the NAO explained only $12 \%$ of the variance (Table 1; Pearson's $r=-0.54$ ) for the same time period. The correlation between $C$. finmarchicus and the NAO was significant for only the first half of data, 1958 to 1980 (Table 1). Thus the correlation between these 2 variables is dominated by their trends, i.e. it was high earlier and has decreased in the latter half of the data set.

The Calanus finmarchicus and NAO time-series are also autocorrelated (Table 1). The NAO is autocorrelated during 1958 to 1992 and for the whole period 1958 to 2002, whereas C. finmarchicus abundance is autocorrelated during all time segments (Table 1). After trend removal, the autocorrelation at lag 1 in $C$. finmarchicus remained strong, while the autocorrelation in the NAO time-series was no longer present (Table 1). C. finmarchicus autocorrelation was not significant during the time period 1981 to 2002 (Table 1). We used the partial autocorrelation function (PACF) to differentiate between autocorrelations in $C$. finmarchicus abundance and in the NAO. The PACF is an extension of the correlation function where the dependencies on the intermediate lags are removed (Shumway \& Stoffer 2000). A statistically significant correlation between the NAO and itself lagged $1 \mathrm{yr}$ was present for the entire time period (1958 to 2002) (Table 1). This trend and a significant correlation at a lag of $5 \mathrm{yr}(\mathrm{r}=0.38, \mathrm{p}=0.05)$ can be interpreted as a quasi-oscillation of this period in the NAO (Fig. 2a). $C$. finmarchicus also shows an autocorrelation at lag 1 , but it is much stronger than that of the NAO (Table 1, Fig. 2b). This indicates a stronger autocorrelation than in the NAO, and lack of other significant lags indicates the lack of multi-year oscillation in the $C$. finmarchicus time-series. The autocorrelation of 0.88 with 1 yr lag suggests another possibility for explaining the variation in C. finmarchicus abundance.

Calanus finmarchicus with $1 \mathrm{yr}$ lag and the NAO can be used as independent variables in a linear regression equation as they are not correlated for any time period (Pearson's $r=-0.28$ to $0.14, \mathrm{p}>0.21$ ). The regression equation for the time period 1958 to 2002 is:

$$
\mathrm{Cf}=0.0009+0.5739\left(\mathrm{Cf}_{\text {lag1yr }}\right)-0.0131(\mathrm{NAO})
$$

where $\mathrm{Cf}$ is $\mathrm{C}$. finmarchicus abundance residuals after trend removal, $\mathrm{Cf}_{\text {lag1yr }}$ is $C$. finmarchicus abundance residuals for the previous year after trend removal and NAO is the December to March value of the NAO index residuals after trend removal. The $p$-values of the regression coefficients are all less than 0.05. The majority of the variance in $C$. finmarchicus abundance

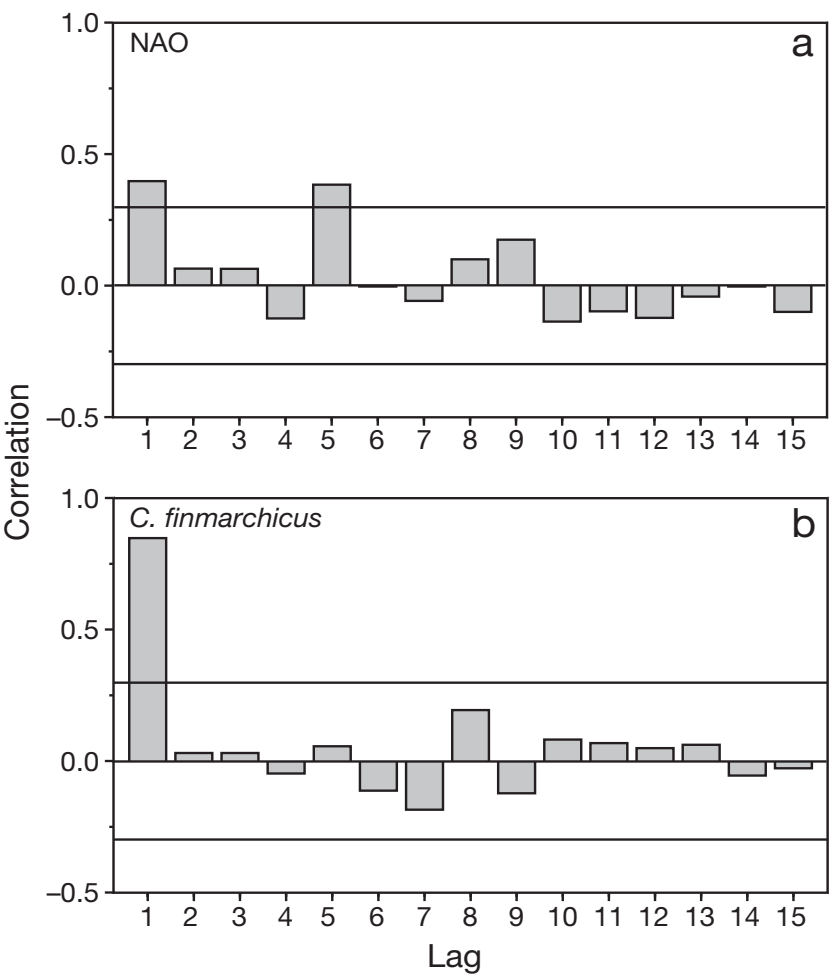

Fig. 2. Partial autocorrelation at multiple lags for the (a) NAO and (b) Calanus finmarchicus abundance. Horizontal black lines: $95 \%$ confidence interval 
is explained by the previous year's abundance (semipartial $\mathrm{r}^{2}=0.36$ ) and not the NAO (semi-partial $\mathrm{r}^{2}=$ 0.08). C. finmarchicus abundance residuals calculated by this regression compared well with the observed abundance residuals from 1958 to 2002 (Fig. 3). This result is a significant improvement on a regression using the NAO index as the lone predictor variable (Table 2). The same regression equation for the time period 1958 to 1992 explained $51 \%$ of the variance in C. finmarchicus abundance residuals (Table 2). Both subperiods of data had significant regression equations and explained at least $26 \%$ of the variance in $C$. finmarchicus abundance. All of this explained abundance in the 1981 to 2002 time period was a function of the prior year's $C$. finmarchicus abundance (Table 2).

\section{DISCUSSION}

The detection of causal relationships between 2 time-series is not straightforward. Ecological timeseries are often non-stationary, i.e. they possess a trend or have serial autocorrelation (Jassby \& Powell 1990). The presence of either can obscure relationships be-

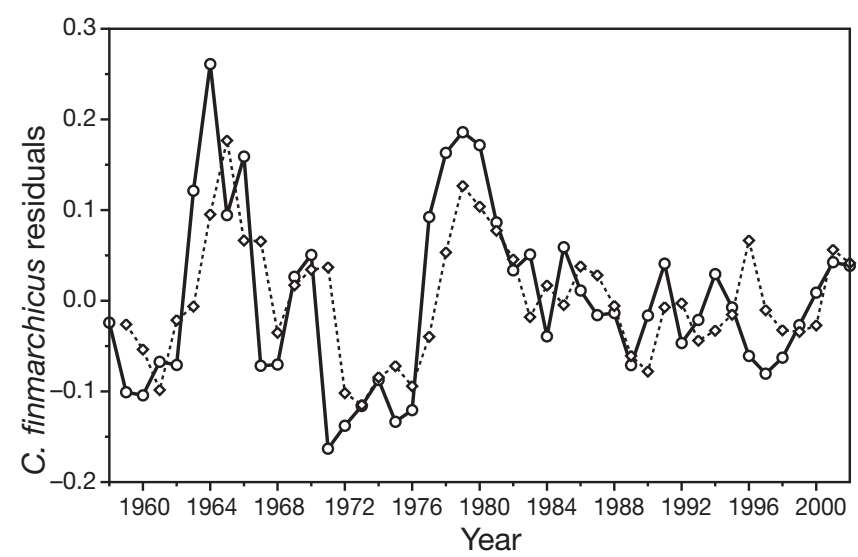

Fig. 3. Calanus finmarchicus. Time-series of the residuals of copepod $(O)$ abundance after trend removal and $C$. finmarchicus residuals predicted $(\diamond)$ from the regression model in the text

Table 2. Linear regression coefficients of determination $\left(\mathrm{r}^{2}\right)$ and model $\mathrm{p}$-values for various regression equations: (1st column) $C$. fin $=a(\mathrm{NAO})+C_{i}(2$ nd column) $C$. fin $=a(C$. fin. $\operatorname{lag} 1 \mathrm{yr})+c_{i}(3 \mathrm{rd}$ column $) C$. fin $=a(C$. fin. lag $1 \mathrm{yr})+b(\mathrm{NAO})+C$. Bold values are significant at $\mathrm{p}<0.05$. $a$ and $b$ are regression coefficients and $c$ is the intercept

\begin{tabular}{|llll|}
\hline Time period & NAO & C. fin. lag $1 \mathrm{yr}$ & NAO + C. fin. lag $1 \mathrm{yr}$ \\
\hline $1958-2002$ & $\mathbf{0 . 1 2}(\mathbf{0 . 0 2})$ & $\mathbf{0 . 3 6}(\mathbf{0 . 0 0 0 1})$ & $\mathbf{0 . 4 4}\left(\mathbf{6} \times \mathbf{1 0}^{-\mathbf{6}}\right)$ \\
$1958-1992$ & $\mathbf{0 . 2 3}(\mathbf{0 . 0 0 3})$ & $\mathbf{0 . 3 6}(\mathbf{0 . 0 0 0 2})$ & $\mathbf{0 . 5 1}(\mathbf{0 . 0 0 0 0 1 )}$ \\
$1958-1980$ & $\mathbf{0 . 3 4}(\mathbf{0 . 0 0 3})$ & $\mathbf{0 . 3 9}(\mathbf{0 . 0 0 2})$ & $\mathbf{0 . 5 7}(\mathbf{0 . 0 0 0 3})$ \\
$1981-2002$ & $0.003(0.81)$ & $\mathbf{0 . 2 7}(\mathbf{0 . 0 1})$ & $\mathbf{0 . 2 6}(\mathbf{0 . 0 5 )}$ \\
\hline
\end{tabular}

tween 2 time-series or produce relationships between time-series that are spurious. Our findings show that the relationship between NAO and Calanus finmarchicus abundance in the northeast Atlantic is weaker than previously thought. The strong correlation between C. finmarchicus abundance and the NAO shown by Fromentin \& Planque (1996) was largely the result of opposing trends present in both time-series. Fromentin \& Planque (1996) noted that trends were present in the data and performed trend removal in the NAO data set using a third-order, polynomial fit. However, they did not remove the significant trend present in the $C$. finmarchicus abundance time-series (Table 1). In addition to the presence of a trend, both time-series showed significant autocorrelation (Table 1). After trend removal using least-squares regression, the autocorrelation in the NAO time-series was no longer present; however, the $C$. finmarchicus time-series remained significantly autocorrelated (Table 1). This, coupled with a partial autocorrelation analysis that revealed autocorrelation in the C. finmarchicus abundance occurring only at a lag of $1 \mathrm{yr}$, suggested that interannual variability in C. finmarchicus is largely a function of the prior year's abundance. There are other reported examples where the previously postulated couplings of phenomena over the North Atlantic with the NAO have deteriorated as the NAO trend has changed direction since the mid-1990s. This was noted for the Gulf Stream northwall by Hameed \& Piontkovski (2004) and for the export of Saharan dust to the Atlantic Ocean by Riemer et al. (2006).

We found that the significant autocorrelation present in the Calanus finmarchicus time-series could be used in a regression equation. By including the prior year's abundance of $C$. finmarchicus into the regression between NAO and C. finmarchicus abundance, we found a significant relationship. This relationship matched the $C$. finmarchicus abundance closely including in the years post-1996, when it appeared that the relationship between $C$. finmarchicus and NAO had broken down (Fig. 3). However, when data were limited to the most recent 22 yr period (1981 to 2002), the addition of the NAO into the regression equation did not explain any additional variance in C. finmarchicus abundance. The prior year's abundance was still able to explain a statistically significant fraction of the variance in $C$. finmarchicus abundance $(26 \%)$; however, it appears that the auto- correlation in the timeseries has significantly weakened.

The tight coupling seen between Calanus finmarchicus in adjacent years is most likely a result of the number of $C$. finmarchicus that enter dor- 
mancy in the fall and overwinter. C. finmarchicus, similar to other calanoid species, survives winter conditions by entering a dormant state characterized by low metabolic demand (Dahms 1995). The CV stage copepodites migrate to depth and lie dormant until spring (Hirche 1996). Emergence from dormancy appears to be related to photoperiod (Speirs et al. 2006), with a possible secondary trigger that causes arousal at depth (Miller et al. 1991). However, recent work suggests that no single environmental cue consistently explains entry or emergence from dormancy (Johnson et al. 2008). The primary mechanism determining entry into dormancy was hypothesized to be a function of the ability of individual $C$. finmarchicus to accumulate adequate lipid reserves (termed the lipid accumulation window hypothesis) (Johnson et al. 2008).

Exit from dormancy is thought to be a function of lipid consumption (Saumweber \& Durbin 2006). Saumweber \& Durbin (2006) predicted emergence from dormancy for Calanus finmarchicus populations in the Gulf of Maine based on animal length, oil sac volume and in situ temperature. They suggest that temperature is the primary environmental determinant because it regulates metabolic consumption of lipid stores, thereby forcing copepods to emerge from dormancy when the energy stored in these lipids is exhausted. Heath et al. (2000) concluded that seasonal cycles of food and temperature, combined with a proximity to overwintering habitats, determined the productivity of $C$. finmarchicus locally. It is this locally produced C. finmarchicus population that enters dormancy during the fall after accumulation of sufficient lipid reserves and thereby determines, to a large degree, the abundance for the next year.

It now appears that the strong connection between year-to-year populations of Calanus finmarchicus is weakening. This may be due to a variety of factors. For instance, the population of $C$. finmarchicus in the northeast Atlantic may have been pushed in one direction by long-term trends in local production that are related to temperature. C. finmarchicus is typically found in lower temperatures and is considered an indicator of the Artic Polar Biome (Helaouet \& Beaugrand 2007). C. finmarchicus growth and development are coupled to temperature (Sundby 2000, Campbell et al. 2001); therefore, a long-term increasing trend in temperature may explain the long-term decline in C. finmarchicus populations. Levitus et al. (2005) presented data on increases in heat content of the oceans from surface to $3000 \mathrm{~m}$ depth for 1955 to 2003. Their results show that the North Atlantic water mass is heating faster than any of the other basins. The 1000 to $3000 \mathrm{~m}$ layer of the North Atlantic added $1.3 \times 10^{22} \mathrm{~J}$ of heat during this period. The analysis of Levitus et al. (2005) is for the entire North Atlantic, but it suggests that a

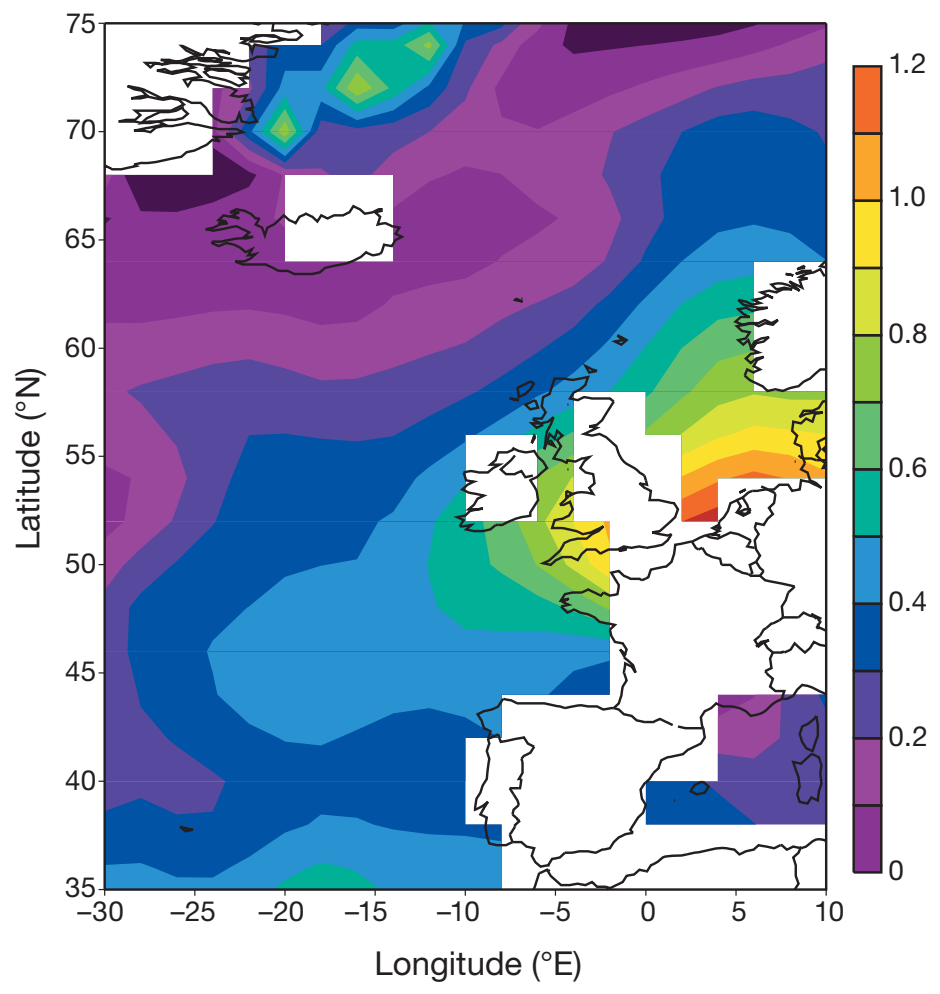

Fig. 4. Sea surface temperature (SST, $\left.{ }^{\circ} \mathrm{C}\right)$ differences between the time periods 1998 to 2002 and 1950 to 1954 . Note all differences are positive, indicating a warming trend since 1950

significant warming trend is taking place in the deep ocean of the CPR region where $C$. finmarchicus overwinters. There have also been changes in sea surface temperature (SST) over the CPR region between two 5 yr periods (1950 to 1954 and 1998 to 2002), using NOAA's extended SST data set (Fig. 4). It shows that the surface has warmed throughout the region. Heath et al. (1999) proposed that the decline of $C$. finmarchicus abundance was a result of a reduction in overwintering habitat available due to a decrease in the volume of Norwegian Sea Deepwater. Warm-water zooplankton species have become prevalent in this region (Beaugrand et al. 2002, Beaugrand 2003). However, other factors, such as natural mortality and mortality due to predation, may be causing the breakdown (Ohman et al. 2004). While it is unclear what is driving this long-term decline in the $C$. finmarchicus population in the northeast Atlantic, it is apparent that it has uncoupled $C$. finmarchicus abundance from the NAO.

\section{CONCLUSIONS}

A reexamination of the Calanus finmarchicus-NAO relationship shows that the correlation between the 2 time-series was largely the result of 
trends present in both series. The correlation between $C$. finmarchicus and NAO remained significant after trend removal; however, the presence of autocorrelation in the $C$. finmarchicus abundance time-series remained. We used this autocorrelation in a regression model and found that it explained the majority of year-to-year variability in C. finmarchicus abundance. We suggest that the connectivity between $C$. finmarchicus populations in adjacent years is a function of the overwintering $\mathrm{CV}$ copepodites. After trend removal, and accounting for autocorrelation, the NAO still explains a small, but statistically significant, portion of the variance in C. finmarchicus abundance. Examination of a more recent time period (1981 to 2002) revealed that the NAO no longer explains variance in $C$. finmarchicus abundance and that though the prior year's abundance of $C$. finmarchicus still explained a significant portion of the variance in $C$. finmarchicus abundance, this relationship appeared to be weakening. We suggest that the weakening connection between year-to-year populations of $C$. finmarchicus in the northeast Atlantic may be a function of long-term warming of the northeast Atlantic or other factors, such as mortality, that are more difficult to quantify.

Acknowledgements. The authors thank K. Hozyash, J. J. Pierson and M. R. Roman for comments. The authors also thank the Sir Alistair Hardy Foundation for Ocean Science, operators of the Continuous Plankton Recorder Survey (www.sahfos. org). Three anonymous reviewers provided comments that greatly improved the manuscript.

\section{LITERATURE CITED}

Beaugrand G (2003) Long-term changes in copepod abundance and diversity in the north-east Atlantic in relation to fluctuations in the hydroclimactic environment. Fish Oceanogr 12:270-283

> Beaugrand G, Reid PC, Ibanez F, Lindley JA, Edwards M (2002) Reorganization of north Atlantic marine copepod biodiversity and climate. Science 296:1692-1694

Campbell RG, Wagner MM, Teegarden GJ, Boudreau CA, Durbin EG (2001) Growth and development rates of the copepod Calanus finmarchicus reared in the laboratory. Mar Ecol Prog Ser 221:161-183

Cushing DH, Dickson RR (1976) The biological response in the sea to climatic changes. Adv Mar Biol 14:1-122

Dahms HU (1995) Dormancy in the Copepoda - an overview. Hydrobiologia 306:199-211

Fromentin JM, Planque B (1996) Calanus and environment in the eastern North Atlantic. II. Influence of the North Atlantic Oscillation on C. finmarchicus and C. helgolandicus. Mar Ecol Prog Ser 134:111-118

Hameed S, Piontkovski S (2004) The dominant influence of the Icelandic Low on the position of the Gulf Stream northwall. Geophys Res Lett 31:L09303

Heath MR, Backhaus JO, Richardson K, McKenzie E and others (1999) Climate fluctuations and the spring invasion of the North Sea by Calanus finmarchicus. Fish Oceanogr 8: 163-176

Heath MR, Astthorsson OS, Dunn J, Ellertsen B and others (2000) Comparative analysis of Calanus finmarchicus demography at locations around the Northeast Atlantic. ICES J Mar Sci 57:1562-1580

> Helaouet P, Beaugrand G (2007) Macroecology of Calanus finmarchicus and $C$. helgolandicus in the North Atlantic Ocean and adjacent seas. Mar Ecol Prog Ser 345:147-165

Hirche HJ (1996) Diapause in the marine copepod, Calanus finmarchicus-a review. Ophelia 44:129-143

Hollowed AB, Hare SR, Wooster WS (2001) Pacific Basin climate variability and patterns of Northeast Pacific marine fish production. Prog Oceanogr 49:257-282

Hurrell JW (1995) Decadal trends in the North Atlantic Oscillation: regional temperatures and precipitation. Science 269:676-679

Jassby AD, Powell TM (1990) Detecting changes in ecological time-series. Ecology 71:2044-2052

Johnson CL, Leising AW, Runge JA, Head EJS, Pepin P, Plourde S, Durbin EG (2008) Characteristics of Calanus finmarchicus dormancy patterns in the northwest Atlantic. ICES J Mar Sci 65(3):339-350

Jossi JW, John AWG, Sameoto D (2003) Continuous Plankton Recorder sampling off the east coast of North America: history and status. Prog Oceanogr 58:313-325

> Levitus S, Antonov J, Boyer T (2005) Warming of the world ocean 1955-2003. Geophys Res Lett 32:L0260

> Miller CB, Cowles TJ, Wiebe PH, Copley NJ, Grigg H (1991) Phenology in Calanus finmarchicus: hypotheses about control mechanisms. Mar Ecol Prog Ser 72:79-91

> Ohman MD, Eiane K, Durbin EG, Runge JA, Hirche HJ (2004) A comparative study of Calanus finmarchicus mortality patterns at five localities in the North Atlantic. ICES J Mar Sci 61:687-697

> Ottersen G, Planque B, Belgrano A, Post E, Reid PC, Stenseth NC (2001) Ecological effects of the North Atlantic Oscillation. Oecologia 128:1-14

Parsons LS, Lear WH (2001) Climate variability and marine ecosystem impacts: a North Atlantic perspective. Prog Oceanogr 49:167-188

Pearcy WG, Schoener A (1987) Changes in the marine biota coincident with the 1982-1983 El Niño in the northeastern subarctic Pacific Ocean. J Geophys Res 92:14417-14428

> Planque B, Fromentin JM (1996) Calanus and environment in the eastern North Atlantic. I. Spatial and temporal patterns of C. finmarchicus and C. helgolandicus. Mar Ecol Prog Ser 134:101-109

Planque B, Reid PC (1998) Predicting Calanus finmarchicus abundance from a climatic signal. J Mar Biol Assoc UK 78: 1015-1018

> Planque B, Taylor AH (1998) Long-term changes in zooplankton and the climate of the North Atlantic. ICES J Mar Sci 55:644-654

Richardson AJ, Walne AW, John AWG, Jonas TD and others (2006) Using continuous plankton recorder data. Prog Oceanogr 68:27-74

Riemer N, Doherty OM, Hameed S (2006) On the variability of African dust transport across the Atlantic. Geophys Res Lett 33:L13814

> Royer TC, Grosch CE, Mysak LA (2001) Interdecadal variability of Northeast Pacific coastal freshwater and its implications on biological productivity. Prog Oceanogr 49:95-111

> Saumweber WJ, Durbin EG (2006) Estimating potential diapause duration in Calanus finmarchicus. Deep-Sea Res II 53:2597-2617 
Shumway RH, Stoffer DS (2000) Time series analysis and its applications. Springer-Verlag, New York

Speirs DC, Gurney WSC, Heath MR, Horbelt W, Wood SH, de Cuevas BA (2006) Ocean-scale modelling of the distribution, abundance, and seasonal dynamics of the copepod Calanus finmarchicus. Mar Ecol Prog Ser 313:173-192

Sugimoto T, Kimura S, Tadokoro K (2001) Impact of El Niño events and climate regime shift on living resources in the

Initial editorial responsibility: Howard Browman, Storebø, Norway; Final editorial responsibility: Matthias Seaman,

Oldendorf/Luhe, Germany western North Pacific. Prog Oceanogr 49:113-127

Sundby S (2000) Recruitment of Atlantic cod stocks in relation to temperature and advection of copepod populations. Sarsia 85:277-298

Taylor AH (1995) North-south shifts of the Gulf Stream and their climatic connection with the abundance of zooplankton in the UK and its surrounding seas. ICES J Mar Sci 52: 711-721

Submitted: May 28, 2007; Accepted: April 14, 2008

Proofs received from author(s): August 20, 2008 